\title{
Marginalidad y vulnerabilidad en Limón ante el riesgo de inundación. Un estudio del Proyecto de Limón Ciudad Puerto ${ }^{1}$
}

\section{Sofía Guevara Víquez²}

\section{Resumen}

Recepción: 28 de noviembre de 2016 / Aceptación: 23 de marzo de 2017

El artículo analiza las relaciones entre los territorios catalogados como vulnerables y marginales en la ciudad de Limón y las instituciones públicas en Costa Rica, en el marco del Proyecto de Limón ciudad Puerto (PLCP). A partir de un trabajo de campo cualitativo, se analizan los espacios abiertos por este proyecto para reducir las inundaciones en dicha ciudad. Se plantea de esta manera la influencia de las prácticas institucionales en la reproducción de la vulnerabilidad de la población de los barrios periféricos de la ciudad Limón. El artículo propone así una reflexión global sobre la manera de lidiar con la problemática del riesgo en las ciudades.

\section{Palabras clave}

Limón Ciudad Puerto; vulnerabilidad; riesgo de inundación; marginalidad; Limón

\section{Abstract}

The article analyzes the relationships between the territories classified as vulnerable and marginal in the city of Limón and public institutions in Costa Rica, within the framework of the Limon City Port Project (PLCP). From a qualitative field work, the spaces opened by this project to reduce the floods in that city are analyzed. The question of the influence of institutional practices in the reproduction of the vulnerability of the population in peripheral neighborhoods of Limón is raised. The article thus proposes a global reflection on how to deal with the problem of risks in cities.

\section{Keywords}

Limon City Port Project; vulnerability; flood risk; marginality; Limon

1 La autora agradece las sugerencias de la M.Sc. Laura Paniagua y de la Dra. Isabel Avendaño en el proceso de redacción del artículo. Se agradece también a Limón, al SENARA, y a toda las personas entrevistadas por el tiempo que dieron a esta investigación.

2 Costarricense. Master en Ciencias Políticas por el Instituto de Ciencias Políticas de Rennes (IEP de Rennes), Francia. Master en Estudio Comparado del Desarrollo por la Escuela de Estudios Superiores en Ciencias Sociales (EHESS) de Paris. Actualmente es doctoranda de la Universidad de Paris Este-Paris Oeste, miembro del Laboratorio Latts, y coordinadora del Instituto de las Américas en la Universidad de Costa Rica. Correo electrónico: guevi.sofia@gmail.com 


\section{Resumo}

O artigo analiza a relacão entre os territorios vulneráveis e marginais na cidade de Limon, e as instituicões costariquenhas, no contexto do Projeto de Limon Ciudad Puerto (Limon Cidade Porto). A partir de uma investigacão qualitativa, o trabalho analiza os espaços abertos pelo projeto para reduzir o problema do risco de inundação. Com isto, se propõe estudar a influência das práticas institucionais na reproducão da vulnerabilidade dos bairros marginais de Limon. $O$ artigo oferece por tanto uma reflexão global sobre a maneira de lidar com o risco de inundção nas cidades.

\section{Palavras chave}

Projeto de Limon Cidade Porto; vulnerabilidade; risco de inundação; marginalização; Limon

\section{Introducción}

Durante el 2014, el gobierno de Costa Rica inicia un proceso de cierre del Proyecto de Limón Ciudad Puerto (PLCP), el cual buscaba dinamizar su principal ciudad portuaria, Limón. Este proyecto, formalizado en el 2009 (ley 8725), se estructura en torno a 13 ejes de intervención y tenía como objetivo "potencializar el desarrollo directo de la ciudad de Limón e indirecto de la región Caribe del país"3, históricamente rezagada 4 . Al respecto podemos recordar la frase de Gonzales: "El país está en deuda con Limón, su principal puerto y fuente de grandes riquezas, pero siempre condenado a estar entre los últimos convidados a los beneficios del desarrollo"5 (La Nación, 2011). Sin embargo, a pesar de sus grandes ambiciones, el PLCP se cierra en diciembre de 2014 sin que se ejecutara la mayor parte de su presupuesto, ni se alcanzaran sus objetivos. Al cerrarse, este proyecto de gran envergadura institucional, reproduce lo que parece ser un fenómeno de abandono recurrente en cuanto a Limón y recuerda las reflexiones de Wacquant sobre la influencia de las prácticas estatales en la reproducción de la marginalidad de ciertos territorios: "Una importante característica de los enclaves de pobreza persistente a los cuales están relegados los parias urbanos de final de siglo XX, es el grado en el que albergan instituciones capaces de satisfacer las necesidades básicas de sus habitantes e incorporarlos a la sociedad global" (2001, p. 247).

El presente artículo reflexiona sobre la manera en que las relaciones estructurales entre población y entidades públicas en el marco del PLCP reproducen la vulnerabilidad de las poblaciones limonenses ante el riesgo de inundación. Se toma como principal escala de análisis uno de los ejes de acción del PLCP: el subcomponente de control de inundación, dirigido por el Servicio Nacional de Aguas, Riego y Avenamiento (SENARA). Este último tiene como misión re-

$3 \quad$ Artículo 2 de la ley 8725 relativa al proyecto de Limón Ciudad Puerto.

4 Para más sobre este tema ver Fernández (2008) y Meléndez y Duncan (2012)

5 González, A.“Ciudad Puerto” La Nación, “Opinión”, 24 de abril de 2011, San José, Costa Rica. 
ducir el impacto de las inundaciones en los barrios más populares de Limón, lo que establece una relación directa entre riesgo y desarrollo en la ciudad. Se trata de mostrar la forma en que la implementación de un proyecto gubernamental de reducción de riesgo de inundación cohabita, interactúa y se inscribe dentro de procesos sociales, institucionales y culturales por medio de los cuales se reproduce las condiciones de riesgo de ciertas poblaciones en los barrios periféricos de Limón.

El objetivo no es, por lo tanto, evaluar las medidas formuladas por el PLCP para reducir las inundaciones, o de evaluar el planteamiento de este en sí, sino el de examinar en qué medida su ejecución, que pretendía ser innovadora, se inscribe dentro de prácticas socio-institucionales conocidas y reproduce los factores de riesgo de la población. Así, el artículo plantea una reflexión sobre las relaciones sociales y la influencia de estas en la reproducción de la vulnerabilidad de ciertas poblaciones ante las inundaciones. Se trata de esclarecer lo que sucede principalmente al interior del subcomponente y lo que llega a concretizarse a los ojos de los habitantes. Para esto, se propone una trayectoria argumentativa que considera las diferentes escalas de actores entrelazadas a la ejecución del subcomponente, es decir que consideramos tanto la escala más global del PLCP, como la escala más local de los habitantes.

Al concentrarse en el estudio de las relaciones entre actores en la implementación de un proyecto de reducción de riesgo, el artículo se inscribe en el linaje de los estudios de la Red Latinoamericana para le reducción de los Desastres (la RED), el cual enfatiza la construcción social del riesgo, y más específicamente, el peso de los procesos sociales en la generación de condiciones de riesgo para ciertas poblaciones en las ciudades (Lavell, 2005; Argüello y Lavell, 2001; García Acosta, 2002). En este enfoque, el riesgo no se explica únicamente por las amenazas naturales, sino, y sobre todo, por las dinámicas sociales que exacerban los impactos de tales amenazas sobre ciertos territorios urbanos. Se toma el concepto de vulnerabilidad como eje central de la reflexión, por cuanto nos permite enfatizar esas dimensiones del riesgo que van más allá de la amenaza natural. Si el riesgo alude a la probabilidad de que una amenaza afecte a una población, el concepto de vulnerabilidad permite visibilizar las condiciones o procesos sociales que influyen en la manera en que la amenaza afecta a un territorio (Lavell, 2005; Leone y Vinet, 2006; García Acosta, 2002), lo que es más pertinente cuando nos encontramos en el contexto de la ciudad.

En efecto, la vulnerabilidad permite subrayar los aspectos sociales, políticos y ambientales que influyen en la producción del riesgo, afectando a poblaciones socio-económicamente marginalizadas, políticamente estigmatizadas y culturalmente excluidas. Estos aspectos se exacerban en el marco de las ciudades (Mansilla, 2000). El artículo hace dialogar, por lo tanto, aportes teóricos de la geografía y de la antropología del riesgo (Leone y Vinet, 2006, Lavell, 2005; Argüello y Lavell, 2001; García Acosta, 2002; Douglas, 1982). Al mismo 
tiempo, el presente documento se inspira de las reflexiones de la sociología urbana de Wacquant (2001), cuyos trabajos sobre la influencia de las relaciones estructurales en la exclusión de ciertos territorios urbanos son esclarecedores en nuestro análisis de la vulnerabilidad de los barrios periféricos de Limón.

De esta manera, después de dar algunos elementos metodológicos y teóricos, se presenta, primero, el panorama de los barrios afectados por las inundaciones en Limón y el contexto de las relaciones entre habitantes e instituciones costarricenses en dicha ciudad. Esta parte se basa en el trabajo de campo, pero también en la literatura existente (Fernandez, 2008; Camaaño, 2006; Municipalidad de Limón, 1992), la cual permite mencionar elementos de la historia de Limón. En efecto, los aspectos histórico-culturales no pueden dejarse de lado cuando se estudian las relaciones entre esta ciudad y la institucionalidad costarricense (Duncan, 1995; Meléndez, 2012). Luego, se presenta el proyecto, el enfoque que este último plantea para reducir las inundaciones. Al existir pocos elementos en la literatura sobre este proyecto, esta parte dedicada al PLCP en sí es importante para entender mejor la decepción que pudo haber generado este último. Finalmente, se examina más específicamente la ejecución del subcomponente de control de inundación. Se demuestra cómo las rivalidades entre instituciones participantes en el subcomponente, los procesos administrativos inoperantes y la imagen negativa que se tiene de los habitantes de los barrios periféricos de Limón, son factores que se articulan en detrimento del avance de dicho proyecto. Estos elementos inscriben al proyecto dentro de una larga historia de incapacidad estatal para responder a las necesidades de esta región.

\section{Elementos metodológicos}

El análisis realizado se basa en un trabajo de observación participante, realizado en el marco de una práctica profesional de abril a septiembre de 2011, dentro del subcomponente de Control de Inundación ${ }^{6}$. Durante estos cinco meses se realizaron varias giras a Limón para entrevistar a los diferentes actores sobre las inundaciones (se realizaron un total de 30 entrevistas). Para completar esta experiencia se realizó un trabajo de campo adicional un año más tarde 7 , en abril de 2012, el cual tuvo como objetivo entrevistar a los representantes del SENARA, analizar el avance del proyecto y detallar las informaciones colectadas anteriormente sobre el problema de las inundaciones y el PLCP. En esta ocasión se realizaron 16 entrevistas y un análisis de los archivos institucionales del SENARA. Como se mencionó anteriormente, el artículo busca mostrar el peso de las relaciones estructurales sobre la vulnerabilidad de las poblaciones, por lo que parte del supuesto que lo importante es poner en evidencia roles y prácticas institucionales que se reproducen y se justifican en el

6 Práctica que tuvo como objetivo formular medidas complementarias a las medidas estructurales propuestas por el PLCP.

7 Bajo el marco de una tesis de maestría 
contexto de Limón, más allá de los individuos. Por posicionamiento teórico no se brindan por consiguiente los nombres de los representantes institucionales, únicamente su función y responsabilidad.

\section{La importancia del concepto de vulnerabilidad social e institucional para entender la incidencia de los riesgos urbanos en Limón}

\section{La vulnerabilidad social e institucional en la generación de riesgos}

Como dicho anteriormente, el artículo plantea el concepto de vulnerabilidad como principal eje de reflexión. Ahora bien, de acuerdo con Leone y Vinet (2006), el concepto de vulnerabilidad, como categoría analítica, permite interrogar diferentes dinámicas de producción del riesgo. Para los autores es posible reflexionar sobre:

-la vulnerabilidad estructural o corporal, que alude a los daños materiales sobre una infraestructura o edificio;

-la vulnerabilidad social, que se refiere a la capacidad de respuesta de las poblaciones ante eventos dañinos. Esta última dimensión interroga las prácticas de las poblaciones ante un determinado evento.

-la vulnerabilidad ambiental, por su parte, interroga el impacto de la amenaza sobre el ambiente ecológico;

-la vulnerabilidad institucional lleva al investigador a analizar la capacidad de respuesta y el peso de las dinámicas institucionales en la generación de riesgo,

-la vulnerabilidad económica y funcional, se refiere al cese de actividades económicas ante una crisis.

Conforme a un abordaje sistémico que toma la complejidad del riesgo, se considera que estas dimensiones no se suman, sino que se articulan entre sí. Es decir, que todas estas dimensiones están activas e interactuando al mismo tiempo. No obstante, para efectos de la demostración, se escoge tomar como eje central de la reflexión, la vulnerabilidad social e institucional de la ciudad de Limón ante las inundaciones urbanas, las cuales considero como dimensiones intrínsecamente relacionadas. Es decir, que la demostración escoge poner énfasis en las relaciones sociales e institucionales para esclarecer dinámicas de reproducción del riesgo en Limón. Desde esta perspectiva, el artículo propone entender las inundaciones y su manejo en el marco del PLCP a la luz del contexto socio-urbano en el que acontecen. Se plantea que la interpretación que se realiza de estos fenómenos dentro del PLCP depende de los actores sociales y de sus estrategias en la ciudad (Bartolomé 2006, García Acosta 2002, Douglas 1982). 
En consecuencia, se considera, siguiendo los aportes de Bartolomé (2006), que la visión hegemónica que logra imponerse del acontecimiento (la inundación) y la manera en que se plantea en el marco del PLCP, llegan a reproducir dinámicas de riesgo en Limón. Al respecto, el autor plantea que el agravamiento de las inundaciones está relacionado a lógicas sociopolíticas que van más allá del evento: "La persistencia de estas prácticas y visiones se asientan en pautas socioculturales específicas de la estructura de poder local, que contribuyen en el proceso de degradación ambiental del entorno urbanorural... aumentando la vulnerabilidad de la ciudad a las inundaciones" (Bartolomé 2006, p. 137). En otras palabras, se plantea que las inundaciones urbanas no son solamente un evento hidrometeorológico en Limón, sino también un evento que plasma prácticas y procesos socio-institucionales que el PLCP no logra cuestionar. Al contrario, los reproduce.

Se analizan estos elementos en el marco del componente de control de inundación del PLCP en la ciudad de Limón, con lo que se espera alimentar la reflexión sobre los riesgos urbanos en la región centroamericana propuesta por investigadores como Caballero (2013), Lungo (2001) y Mansilla (2000). Estos últimos autores enfatizan la influencia de las dinámicas de urbanización desiguales y excluyentes de las ciudades latinoamericanas sobre la vulnerabilidad de las poblaciones socio-económicamente excluidas. Analizar la temática de los riesgos en nuestras ciudades impone, por lo tanto, interrogar la complejidad de estos procesos sociales (que también son culturales y políticos) que se imbrican en el contexto urbano a lo largo del tiempo (Lungo 2001; Mansilla 2000).

Dichos procesos sociales son asumidos por actores que reproducen prácticas y dinámicas a lo largo de la historia, por lo que el estudio de las relaciones estructurales entre las entidades públicas y los habitantes, dentro de la ciudad de Limón, constituyen una entrada para abordar la complejidad del riesgo urbano. En efecto, "la inundación no se reduce a un fenómeno natural sino que es la cristalización de una construcción colectiva y diferencial del entorno ambiental urbano como escenario de riesgo" (Bartolomé, 2006, p. 134). Tal planteamiento, formulado a partir de los estudios sobre el riesgo, permite dibujar nuevas pistas de reflexión sobre la situación de exclusión en la que se encuentra Limón.

En efecto, tal y como se verá a continuación, por su historia y sus condiciones de vida, las comunidades de los barrios afectados por las inundaciones en Limón (Limoncito, Cieneguita, Los Lirios, Colina) tejen relaciones de carácter conflictivo con las entidades públicas. Se trata de comunidades que se desarrollan espontáneamente a las riberas del río Limoncito, en áreas consideradas como de riesgo, en territorios que los representantes institucionales califican de "informales", lo que pesa en la manera como se plantea el riesgo de inundación en el marco del proyecto. 


\section{Limón, una región costarricense marginalizada}

La historia del desarrollo de Limón y de la región Atlántica esclarece las representaciones ${ }^{8}$ que tanto los habitantes de Limón como los representantes institucionales tienen actualmente de esta ciudad, cuna de la cultura afrocaribeña de Costa Rica. La ciudad fue fundada en 1870 y su desarrollo se encuentra relacionado, en gran medida, con la construcción del ferrocarril y con la actividad bananera de finales del siglo XIX, para las cuales se favoreció la inmigración de poblaciones de las Antillas (Camaaño, 2006). Esta inmigración fue regulada por el Estado costarricense; tan es así que, cuando la producción bananera se desplaza hacia el sur del país en 1932 y la economía agraria de la región entra en crisis, el Estado de Costa Rica prohíbe la contratación de población afrodescendiente en el sur con el objetivo de limitar la expansión de esta población fuera de Limón. Al respecto existe, en la memoria de la población limonense y en la de los costarricenses, una ley que prohíbe a los afrodescendientes ir más allá de la Región Atlántica, a pesar de que los historiadores no hayan podido aún encontrar la codificación oficial de esta prohibición (Fernández, 2008). Durante el trabajo de campo, se pudo observar como esta frontera cultural pesa sobre las representaciones que tienen los habitantes de sí mismos y sobre las que tienen los representantes institucionales en relación con Limón, tal y como lo veremos más tarde:

Mis padres vivían aquí en Limón ... pero ellos se fueron para el campo, porque ... ¿Sabe por qué ellos se tuvieron que ir? Porque en las escuelas de aquí, de Limón, solo las blancas podían ir a la escuela, y a las personas negras las dejaban afuera. Entonces, entonces mi papá no supo hablar español ... era como en los tiempos que nosotros, los de Limón, no podíamos pasar de Siquirres (P., representante comunal de Limoncito, 2012).

A lo largo del siglo XX, la región no logra salir de su situación de rezago económico y social a pesar de disponer de ventajas en su territorio (Camaaño, 2006). En la ciudad de Limón, cabecera de la región atlántica, se concentran las sedes de las instituciones estatales. La ciudad constituye el principal centro urbano ${ }^{9}$ del caribe costarricense y alberga, además, al primer puerto del país, Moín, el cual representa entre el $80 \%$ y $90 \%$ el flujo comercial del país ${ }^{10}$. A pesar de esta posición estratégica, estudios y diagnósticos constatan la degradación del desarrollo de la región y sus múltiples problemas sociales. Al respecto, el Plan Regional de Desarrollo de la provincia de Limón observa que la región, en comparación con otras del país, se encuentra por debajo del promedio nacional en los indicadores socio-económicos de pobreza. De

$8 \quad$ Para efectos de la demostración, entiéndase representación social como aquel conocimiento socialmente elaborado y compartido que establece una realidad común y tiene fines prácticos (Jodelet, 2000).

9 Su población es de 60045 habitantes. Su extensión urbana de 44,27km² abarca la mayoría de la superficie del distrito primero de Limón, el cual posee un área de 59,76 km².

10 JAPDEVA, Plan regional de Desarrollo de la provincia de Limón, Limón hacia el siglo XXI, potencialidades y Oportunidades para el Desarrollo, 1999-2009. 
acuerdo a este Plan, el: "terremoto que afectó a esta zona en el año de 1991 (22 de abril) ocasionó un rezago significativo a niveles comparables a los generados en la década de los setentas. La recuperación ha sido lenta ... Se han incrementado las inundaciones, el deterioro de la infraestructura regional es considerable"11.

Camaaño (2006) plantea que la región es víctima de los resultados de políticas públicas ejecutadas lo largo del siglo de XX. Estas últimas, de carácter neoliberal, generan una economía de enclave que nunca es verdaderamente cuestionada. Asimismo, en la década de 1950, con la nacionalización del ferrocarril, se genera un proceso de centralización que beneficia la economía capitalina y no la de la provincia caribeña. Con los programas de ajuste estructural de los años 1980, se cierra el ferrocarril y se liberalizan los muelles, lo que genera desempleo y subempleo en la región (Camaaño, 2006).

Así, en el 2009, año en que se firma el contrato de préstamo relativo al PLCP, la situación relativa de la pobreza de la región Huétar Atlántica (28\%) sobrepasa la del resto del país $(21 \%)^{12}$, lo que se prolonga hasta el día de hoy: de acuerdo con el Censo de 2011, la región Atlántica forma parte de las regiones que presentan mayor porcentaje de viviendas en mal estado en Costa Rica (Estado de la Nación, 2012, p. 106). En 2014, el porcentaje de hogares en situación de pobreza es de 28, 2 en la región Atlántica, mientras que en la región central es de 17, 2 y en el país de 21 (Estado de la Nación, 2015, p. 92). Es además la región con mayor proporción de hogares sin acceso a agua y a electricidad (Plan Nacional de Desarrollo, 2015-2018). Asimismo, la situación de violencia es grave en el cantón central. Entre 2003 y 2013 la ciudad de Limón forma parte de las comunidades que, en promedio, registraron las tasas más altas de homicidios ${ }^{13}$, por lo que es una de las diez comunidades prioritarias en este ámbito dentro del Plan Nacional de Desarrollo 2011-2014. En 2016, después de episodios de violencia en Cieneguita, un representante de Seguridad Pública habla inclusive de "provincia fallida" en los medios de comunicación ${ }^{14}$.

\section{La vulnerabilidad de Limón ante las inundaciones: un problema de los territorios marginales y "conflictivos"}

Aunada a estas problemáticas sociales, la ciudad de Limón sufre recurrentemente de inundaciones del río Limoncito, relacionadas al contexto pluviométrico, un nivel freático alto y una baja capacidad de absorción de los sistemas de dre-

11 JAPDEVA, Plan regional de Desarrollo de la provincia de Limón, Limón hacia el siglo XXI, potencialidades y Oportunidades para el Desarrollo, 1999-2009.

12 JAPDEVA, 2011, Plan Regional de Desarrollo 2012-2022, Documento 1, Diagnóstico. Estas cifras son reiteradas por el Balance del vigésimo Informe del Estado de la Nación (2014), el cual hace un balance de la evolución del país en los últimos 20 años.

13 Junto con Garabito, Matina, Tibás, Corredores y San José. Estado de la Nación (2014). Vigésimo Informe, p. 91.

14 Noticias RTN, 6 de octubre de 2016. Véase https://socialfeed.info/es-limon-una-provincia-fallida-asilo-afirma-el-experto-en-seguridad-5707887 
naje en la ciudad. Estas inundaciones afectan principalmente, como se observa en la Figura 1, a las poblaciones de los barrios periféricos de la ciudad, que se inundan generalmente de 1 a 2 veces por año. La zona más afectada corresponde al punto donde desemboca la Quebrada Chocolate en el Río Limoncito; aquí, los eventos de inundación se pueden dar más de dos veces por año (Nahassia, 2011).

Figura 1. Zonas que se inundan en el área de estudio

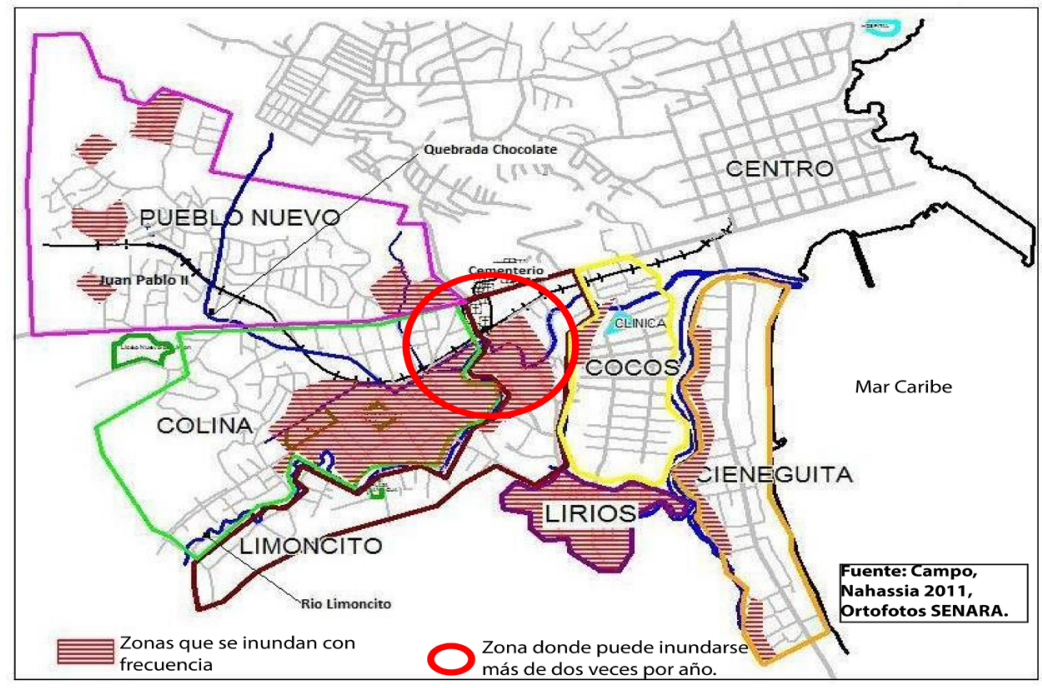

Fuente: Guevara Víquez (2011)

Con la excepción de Cieneguita, dichos barrios periféricos surgen de tomas de terreno (Pueblo Nuevo en 1962, Limoncito en 1965, La Colina en 1967) y crecen bajo una urbanización no planificada (Arroyo Gonzáles, 1996), con poco equipamiento social, lo que alude a las reflexiones de Caballero (2013) sobre la vulnerabilidad en las ciudades latinoamericanas, producto de los factores de exclusión social. El informe de diagnóstico para Limón Ciudad Puerto de la FLACSO afirma en este sentido:

El sector al sur de la ruta 32, contiene los barrios más populosos ... Este sector concentra los problemas más serios de habitabilidad pues la parte alta (La Colina) es susceptible de deslizamientos durante la temporada de lluvias, los barrios más bajos se inundan varias veces al año ... Las viviendas, construidas a ras del terreno, plano y arcilloso, se anegan ... El que no existan alcantarillas pluviales y sanitarias, complica la situación ya que la inundación torna las fosas sépticas inútiles y la inundación es con aguas altamente contaminadas. Hay muchas calles sin pavimentar y las que lo están se encuentran en muy mal estado( Limón Ciudad Puerto. Informe de consultoría, 2004, p. 13).

En otras palabras, el riesgo de inundación en estos barrios se inscribe en un contexto de desigualdad de acceso a servicios básicos y vivienda. Para varios de los representantes institucionales, las inundaciones están altamente relacionadas con esta historia del desarrollo urbano, que a pesar de 
haberse consolidado en muchos de los casos (Limoncito, Los Cocos, Colina) tienen un origen problemático:

Parte de los problemas que se han dado con las inundaciones es que la gente se fue a vivir a donde eran los humedales. Asentamientos que eran humedales, que eran Los Cocos, era Los Lirios, era la parte de atrás de Cieneguita, Ceibón. O sea, todo eso era una parte donde el río Limoncito, Chocolate y todo dejaba su afluencia y agua, y ahí eran humedales. Y ahora, por cuestiones de...la gente ha rellenado y fue entrando y fue entrando... Las últimas comunidades que se han formado en los últimos 10 años han sido Los Lirios, que ha creado otro impacto...Puede ser un proceso que lleva unos 30-35 años... Es un problema de falta de ordenamiento urbanístico, ¿verdad? La gente necesita donde vivir, y la gente va a vivir, aunque hagan las casas en balsas. Pero es una cuestión de subsistencia (Representante de la Municipalidad de Limón, abril de 2012).

Para este funcionario de la Municipalidad, el problema de las inundaciones se encuentra, por lo tanto, ligado al origen del poblamiento de esos barrios, es decir, a la manera como los habitantes se establecen en esas zonas de riesgo, al margen de lo formal, sin ninguna planificación. En otras palabras, dicho problema se encuentra, según el representante de la Municipalidad, relacionado con las áreas marginales e informales ${ }^{15}$ de la ciudad. Ahora bien, es justamente ese carácter "informal" del desarrollo de estos barrios que determina las relaciones conflictivas ${ }^{16}$ entre estas poblaciones y las entidades públicas, pues el acceso a los servicios públicos de estos sectores populares se ha realizado al cabo de movimientos de luchas realizados por la población (Camaaño 2006; Municipalidad 1992).

Este contexto conflictivo es generado por la incapacidad de las entidades públicas de responder a una demanda social de servicio básico, lo que se pudo constatar durante el trabajo de campo. Los Lirios, por ejemplo, es un asentamiento que surge en 1989. En este barrio, las viviendas no tuvieron acceso al agua potable durante varios años. El conflicto con el Instituto Costarricense de Acueductos y Alcantarillados (AyA) se prolongó por varios años, pues no se realizaban las conexiones a las casas y las conexiones colectivas presentaban problemas. En 2008 se habla de otro proyecto interinstitucional ${ }^{17}$, pero ante el poco avance de este último, la comunidad presenta un recurso de amparo a la sala IV, en 2012, el cual es declarado sin lugar ${ }^{18}$.

Volaron 700 millones de colones en estupideces ... cuando se fue a pedir el trabajo, se comisionó a gente para ir a pedir el trabajo porque se suponía que sabíamos lo que queríamos que ellos vinieran a hacer. No que ellos vengan a batearnos, a hacer lo que ellos les diera la gana (Entrevista de Y., representante comunal de Bananito, 2012).

15 Cuando se utiliza el término "informal" la investigación toma como punto de referencia el marco legalformal de la normativa costarricense, que considera estas tomas de terreno como "irregulares".

16 Entiéndase por "conflictos" las tensiones generadas por una situación de exclusión que sufren algunas poblaciones de sectores populares y la movilización de estas para reducir dicha situación de exclusión ante la falta de acción de las entidades públicas. El término no se refiere a episodios de violencia abierta.

17 Plan nacional de Erradicación de Precarios, Minuta de Reunión n², 2/05/2008, Limón.

18 Sala Constitucional, Sentencia n¹1985, 31 de agosto de 2012. 
Así, el estudio de la vulnerabilidad de Limón ante las inundaciones urbanas permite mostrar cómo este fenómeno deja ver una serie de desigualdades socio-económicas en la ciudad. Las inundaciones afectan principalmente a las poblaciones más pobres y excluidas dentro de una región ya marginalizada en el contexto costarricense. Por ocurrir / acontecer en los sectores considerados como "informales", este fenómeno se inscribe además en un contexto de relaciones conflictivas entre la población y la institucionalidad costarricense. Es en el marco de estas relaciones que el Proyecto de Limón Ciudad Puerto se viene a inscribir y a partir de ellas que el proyecto toma forma.

\section{EI PLCP, un proyecto innovador}

\section{Soluciones ante las inundaciones en Limón: entre \\ intervenciones puntuales y estrategias de sobrevivencia}

Antes del PLCP, la respuesta institucional para reducir la vulnerabilidad de la ciudad ante las inundaciones urbanas se enfoca en el manejo del evento, interviniendo sobre el río directamente, intentando aumentar la capacidad de drenaje de este último en ciertos puntos o dragándolo. Se trata de medidas institucionales de tipo paliativo que siguen un marco de acción centrado en intervenciones de ingeniería civil, las cuales, tienen un impacto a mediano plazo. La mayoría de las veces, estas intervenciones se realizan a solicitud de las mismas comunidades que, como ya se mencionó, poseen una larga trayectoria de movilización social (Municipalidad, 1992). La figura 2 muestra las diferentes intervenciones que se han realizado ${ }^{19}$.

Figura 1. Resumen de las intervenciones del MOPT y JAPDEVA para reducir la afectación de las inundaciones en Limón

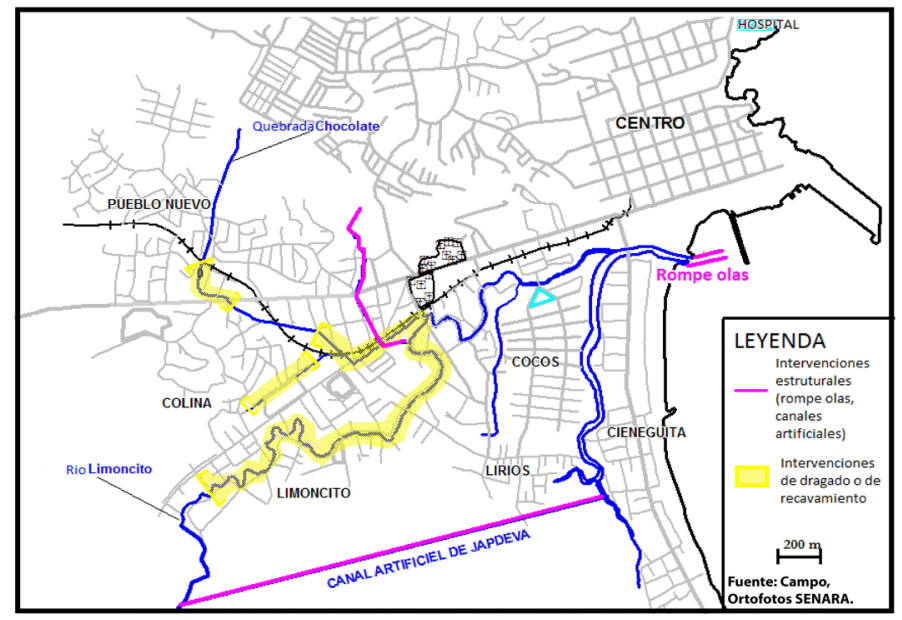

Fuente: Guevara Víquez (2011)

19 De acuerdo a los datos colectados por las entrevistas: el canal artificial de JAPDEVA se realiza a inicio de los años 1990, el rompeolas se realiza en los años 2000, y las operaciones de dragado del río se realizan entre el 2005 y el 2010. 
Por su parte, las poblaciones han desarrollado estrategias de adaptación (Quesada, 2012) y crean nuevas barreras simbólicas que permiten inscribir el riesgo de inundación dentro del cotidiano propio de la urbanidad (Beuscart y Peerbaye, 2003) de Limón, entendida como la condición de estar y vivir en la ciudad. Por ejemplo, durante la época de las inundaciones, los habitantes dejan los muebles en alto, vigilan la cantidad de agua que cae, se acostumbran a solo llegar a dormir a la casa y dejan algunos electrodomésticos en casa de amigos. Los habitantes también relativizan las llenas frecuentes, de baja intensidad, en comparación a las grandes inundaciones que se dan en otros lugares: "aquí no es como en Estados Unidos" (P., vecina de Limón, abril 2012). Esta banalización permite ciertamente lidiar con el día a día y reduce la impresión del riesgo en el seno de la población. Dentro del análisis de estas estrategias, se debe considerar que el riesgo es importante puede significar también, para las poblaciones, aceptar el carácter ilegítimo de su presencia en el territorio (Coanus, Duchêne, Martinais, 1999), lo cual resulta difícil para territorios consolidados a lo largo del tiempo.

Sin embargo, esta banalización también contribuye a perpetuar las desigualdades ambientales (Blanchon, Gardin, Moreau, 2011) a las cuales están sujetos los barrios periféricos, siempre afectados por inundaciones y contribuye a crear una especie de estatu quo entre entidades y habitantes. Al respecto, se pueden citar los enfoques de García Acosta (2002) y de Douglas (1982), para quienes la percepción del riesgo depende siempre de un sistema social que pone el énfasis en un evento dado en función de las estrategias y de las representaciones de los diferentes actores. Por un lado, al no poder tratar las problemáticas sociales de los barrios periféricos, las instituciones enfatizan ampliamente el peligro de trabajar en esas zonas y la ilegitimidad del origen de los asentamientos. Por el otro, los habitantes, limitados por sus recursos, banalizan el riesgo.

Es en este marco que el PLCP pretende proponer un enfoque nuevo, el cual pretende ser integrado y multisectorial en el manejo de la vulnerabilidad de Limón ante el riesgo hidrológico. El PLCP, aprobado por ley nº 8725 en 2009, busca compensar la situación de marginalidad en que se encuentra la región Atlántica y los habitantes de Limón. Como se dijo anteriormente, no se trata aquí de defender el planteamiento del proyecto en sí. Se trata de presentar en qué medida el PLCP pudo haber sido una respuesta original ante la temática de las inundaciones para luego examinar en qué medida no lo fue. 


\section{El PLCP, "un acto de Justicia"20 ambicioso en su planteamiento}

El PLCP es el producto de un largo proceso de formulación ${ }^{21}$. La idea nace bajo la administración Abel Pacheco (2002-2006), retomada por la administración Óscar Arias (2006-2010), y por la de Laura Chinchilla (2010-2014). La iniciativa se inscribe dentro de una estrategia de desarrollo triple llevada a cabo por el Gobierno en la región Atlántica: la primera estrategia se refiere al tema de la vivienda y al desarrollo social, la segunda a la modernización del puerto; y la tercera, llevada a cabo con el PLCP, busca el mejoramiento del ambiente urbano de la ciudad con el fin de reforzar el atractivo de la misma, siguiendo un enfoque liberal. De esta manera, entre 2002 y 2009 se realizan misiones del Banco Mundial, estudios preliminares (FLACSO 2004; CIAS 2006; Banco Mundial 2003, 2007) que constatan y reafirman la pérdida de competitividad de la ciudad, su degradación y la incapacidad de JAPDEVA y del gobierno local para responder a las necesidades de la ciudad. La publicación de la ley relativa al préstamo contraído por el gobierno de Costa Rica con el Banco Mundial (BM) se hace el 11 de junio de $2009^{22}$.

El objetivo principal formulado por los documentos del BM es colaborar a la trasformación de la ciudad portuaria con el fin de mejorar el ambiente urbano, aumentar la competitividad comercial del país, y permitir recíprocamente el desarrollo económico y social de Limón. Se trata de "potencializar el desarrollo directo de la ciudad de Limón e indirecto de la región del Caribe del país, mediante la creación de sinergias entre la ciudad revitalizada, urbana y económicamente activa, y el puerto, moderno y eficiente"23.

Para ello, el proyecto pretende distinguirse por su ambición a largo plazo, y por sus múltiples ejes de intervención, es decir que se trata de un proyecto liberal que no pretende centrarse únicamente en el aspecto monetario para incentivar el desarrollo (por medio de una simple transferencia de fondos). En su planteamiento, el proyecto busca tomar en cuenta las diferentes interdependencias existentes entre los factores sociales, económicos, políticos y ambientales de pobreza. Para esto, el PLCP posee cuatro ejes de intervención (ver Diagrama 1), llamados componentes, dentro de los cuales tenemos subcomponentes ${ }^{24}$. En cada uno de estos componentes trabajan varias entidades bajo la coordinación de la "Unidad Técnica", creada para llevar la batuta en la ejecución. El primer componente, referente al desarrollo económico, busca

20 Frase de González A., "Ciudad Puerto", La Nación, Opinión, 24 de abril de 2011, San José Costa Rica.

21 Proceso al cual no se alude detalladamente aquí. Sin embargo, cabe indicar que fue un proceso que generó igualmente conflictos, tales como huelgas por parte del sindicato de los trabajadores de JAPDEVA.

22 El proyecto de 78 millones de dólares es financiado, mayoritariamente por el préstamo (72,5millones). El gobierno de Costa Rica aporta 7,1 millones.

23 La Gaceta 112, 11 junio 2009, Ley 8725, Limón Ciudad Puerto.

24 Banco Mundial, (2007) Project Information Document (PID), appraisal stage, Repport No AB2830, p.8 
impulsar la pequeña empresa. El segundo componente busca reforzar las capacidades del gobierno local. El tercero, busca la modernización del puerto y de las instalaciones del ferrocarril. El cuarto, que interesa el presente artículo, de revitalización urbana, toma en cuenta la situación de los barrios periféricos de la ciudad y busca mejorar sus infraestructuras colectivas.

Diagrama 1. El subcomponente de control de inundación dentro del PLCP

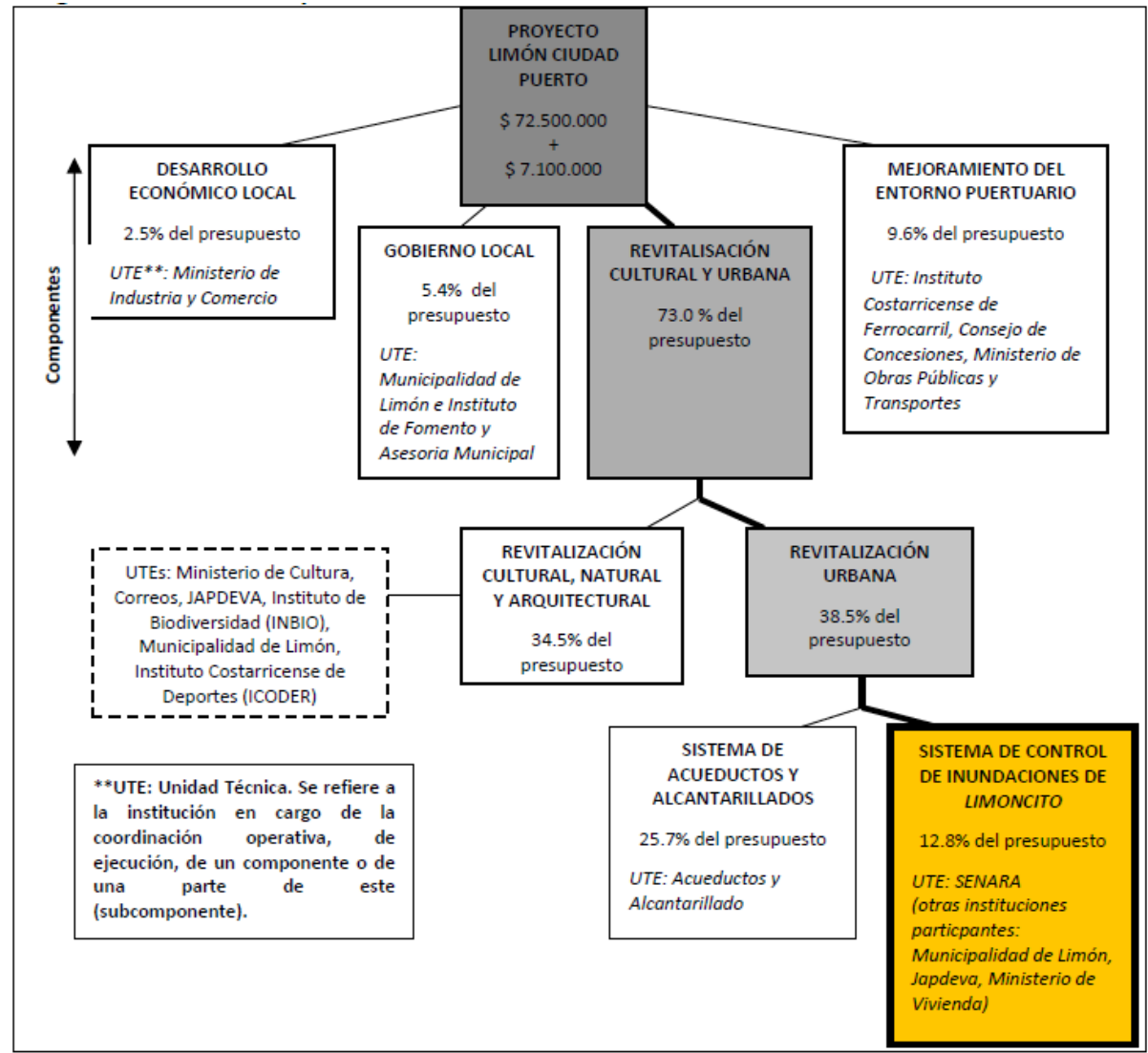

Fuente: Guevara Víquez (2011)

Tal y como lo muestra el Diagrama $1^{25}$, el proyecto pretende ser global y para esto requiere la participación de al menos 15 instituciones diferentes ${ }^{26}$ (ciertas entidades pueden colaborar en varios componentes). A propósito, la Contraloría General de la Republica indica:

por esa misma complejidad que se refleja a lo largo del documento, vemos que éste tiene una trascendencia mayor a la de un mero contrato de préstamo [... .]el préstamo como tal tiene incorporado toda una estrategia que pretende alcanzar un objeto muy

25 En el Diagrama 1 presentamos las UTEs de cada eje de acción, pero detallamos únicamente las instituciones participantes dentro del Subcomponente de control de Inundación.

26 Además de las mostradas en el diagrama encontramos el Ministerio de Hacienda. 
pretencioso, amplio, global e integral, como lo es revitalizar a la ciudad de Limón a partir de un concepto de ciudad-puerto. Ello supone la integración y coordinación de competencias, lo que no siempre es factible por la vía de un contrato de préstamo ${ }^{27}$.

El enfoque llevado a cabo por el proyecto intenta por lo tanto movilizar el conjunto de actores públicos desde diferentes áreas, lo cual lo hace original en relación al conjunto de medidas realizadas hasta ahora. Las soluciones contra las inundaciones, por ejemplo, ya no son realizadas puntual y segmentadamente por una o dos entidades, sino que forman parte de un marco global de acciones para reducir la situación de rezago de la ciudad de Limón. Es dentro de este contexto que el subcomponente de control de inundación se inscribe, con el objetivo de mejorar las infraestructuras colectivas de los barrios periféricos e integrarlos mejor al resto de la ciudad.

\section{El subcomponente de control de inundación: un eje de revitalización de la mano de un actor nuevo en Limón}

Como lo muestra el Diagrama 1, el componente del SENARA se ubica en el eje de revitalización, entendida como "el proceso de mejoramiento dirigido a erradicar las zonas de tugurios y rehabilitar las áreas urbanas en decadencia o en estado defectuoso; y la conservación de áreas urbanas y la prevención de su deterioro"28. El objetivo del componente es entonces, tal y como lo entiende la ley de Planificación Urbana al definir revitalización: contrarrestar el proceso de "decadencia"29 de la ciudad. Este componente se divide a su vez en dos líneas temáticas: la revitalización cultural, arquitectural y patrimonial; y la revitalización urbana, que abarca a su vez la modernización del sistema de saneamiento de la ciudad y el control de las inundaciones, dos sub-componentes que intervienen exclusivamente en los barrios periféricos de Limón. El enfoque del proyecto busca por lo tanto un mejoramiento del "ambiente urbano", entendido como las condiciones de "habitabilidad" de la ciudad, livability" ${ }^{30}$, por medio de acciones directas en los sistemas físicos de servicios de saneamiento de aguas grises y aguas negras.

"Aumentar el acceso a la red de alcantarillado y reducir las inundaciones urbanas en la zona de Limoncito" ${ }^{31}$ permitiría, de acuerdo con el enfoque del proyecto, detener la degradación de las condiciones de vida de los habitantes

27 CGR, oficio 08069-2008 del 7 de agosto de 2008, citado en Contraloría General de la República (CGR), Informe No. DFOE-SAF-IF-03-2012, 20 febrero, 2012: Informe del Estudio sobre la ejecución del Proyecto de Limon Ciudad-Puerto, División de Fiscalización Operativa y Evaluativa, Área de Fiscalización del sistema de Administración Financiera de la República.

28 Ley de Planificación Urbana $n^{\circ}$ 4240, artículo 1.

29 BM, (2007) PAD, p.9.

30 BM, (2007) PAD, p. 10.

31 Ley 8725 , artículo 3. 
de los barrios periféricos. Se establece así una relación directa entre las condiciones de vida de estos barrios y la vulnerabilidad sanitaria y económica de toda la ciudad, es decir que se plantea una interdependencia entre la ciudad y sus barrios periféricos.

Para ejecutar el subcomponente de control de inundación, el PLCP introduce un nuevo actor institucional en el territorio de la ciudad caribeña, el SENARA, el cual debe interactuar con las instituciones históricamente presentes en Limón. Hasta ahora esta institución había intervenido únicamente en las áreas rurales de la región Atlántica. El SENARA debe por lo tanto tratar con las especificidades urbanas del contexto de Limón y llevar un rol protagonista en la ejecución del subcomponente. La solución técnica que plantea dentro de la lógica del proyecto, busca diferenciarse de lo que se había hecho hasta el momento en Limón en cuanto a control de inundación pues promueve una intervención integrada espacialmente, es decir que abarca todo el cauce del río Limoncito al mismo tiempo y no únicamente un solo sector. La idea es ampliar simultáneamente varios puntos de los canales para mejorar el drenaje dentro de la ciudad de Limón, lo que supone el desplazamiento de varias familias limonenses.

En su estrategia, el PLCP parece, por lo tanto, un proyecto innovador en comparación a lo realizado en Limón: busca introducir nuevas dinámicas dentro de un planteamiento multidimensional de la pobreza en las ciudades. Pero, tal y como se analizará en la tercera parte de este artículo, esta ambición debe superar muchos obstáculos. Estos no solo tienen que ver con la estructura organizativa del proyecto, sino que aluden a las relaciones estructurales que se estudiaron en la primera parte del artículo. En efecto, las rivalidades entre instituciones, las problemáticas sociales y culturales relacionadas a la ciudad caribeña se reactivan a lo largo del proyecto. Esta reactivación justifica y legitima la manera en que el proyecto se ejecuta.

\section{El subcomponente de control de inundación y los fantasmas de Limón}

\section{Un proyecto largo con una organización burocrática poco reactiva}

El subcomponente de control de inundación se inscribe en el contexto mayor del PLCP, cuya estructura se visualiza en el Diagrama 2. Esta estructura tiene tres niveles. En la cúspide está el Banco Mundial (BM), el Ministerio de Hacienda y el Comité de Coordinación Interinstitucional, que brinda apoyo en la coordinación ${ }^{32}$. En segundo nivel, se encuentra la Unidad de Coordinación

32 Este último está compuesto por los jerarcas de las instituciones que conforman las UTEs y es presidido por el Ministro de Coordinación Interinstitucional. 
del Proyecto (UCP) y en seguida los componentes y subcomponentes con sus UTEs respectivas. La UCP, órgano de desconcentración máxima del Ministerio de Hacienda está compuesta por veinte personas y es responsable de la coordinación operativa, la supervisión técnica y monitoreo de las adquisiciones.

Diagrama 2. Estructura organizativa del PLCP

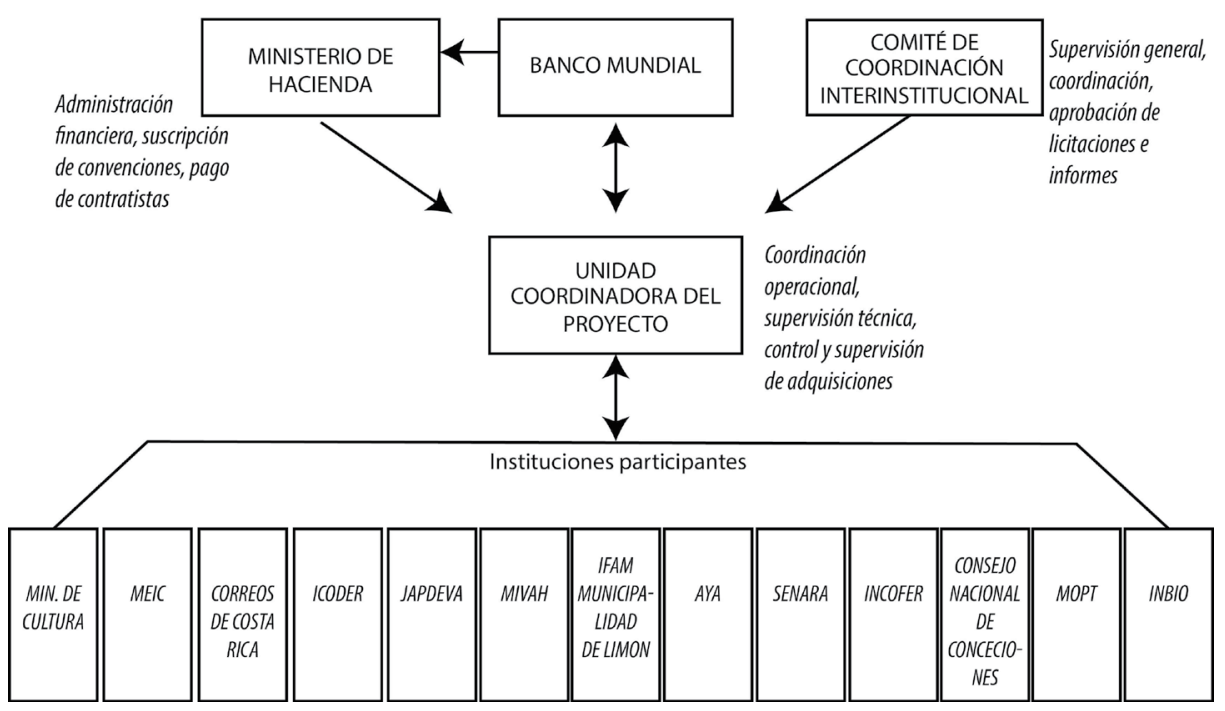

Fuente: Guevara Víquez (2011), con base en la Ley 8725, trabajo de campo, archivos del SENARA.

Esta estructura organizativa presenta varios aspectos inoperantes, sobre todo en cuanto a la relación entre entidades. Toda comunicación entre los componentes y el Banco mundial necesita el visto bueno de la UCP, quien no cuenta a veces con el personal suficientemente capacitado para aconsejar a las UTEs (Fonseca, 2013). Ante esta situación, varias UTEs deciden comunicar directamente con el Banco Mundial (Fonseca, 2013). Además, al interior de cada componente se deben establecer convenios interinstitucionales entre las UTEs y las otras entidades participantes con el objetivo de clarificar los roles de cada una de ellas dentro de cada componente. Estos convenios también deben ser aprobados por la UCP antes de ser comunicados al BM para beneficiar de la no objeción a las condiciones del desembolso. Sólo la firma de dichos convenios demoró cerca de 23 meses en promedio (Fonseca, 2013). Al respecto, Fonseca afirma:

La complejidad del proyecto y la estructura que se creó para llevarlo a cabo constituyen causas importantes en los retrasos en su ejecución. La estructura involucra a quince instituciones en distintos niveles y con alcances variados lo cual ha generado una organización burocrática que se ha enfrentado a problemas de diseño y gestión" (2013, p. 4) ${ }^{33}$.

33 Para más detalle en este aspecto ver Fonseca (2013). 
Asimismo, la formulación de la intervención del sub-componente en sí sufre de muchos cambios. El primer diseño se realiza en base al estudio de la empresa CIAS en 2006, fecha en la que el SENARA aún no había sido asignado como UTE. En ese momento, la entidad en cargo de darle el seguimiento al componente de control de inundación es el Instituto de Acueductos y Alcantarillados. Los primeros contactos con el SENARA se realizan en el 2007, cuando la primera versión de la intervención ya había sido realizada en base a la propuesta de CIAS, con varias deficiencias. Por ejemplo, el número de hogares por desplazar había sido subestimado: se habían contado seis hogares ${ }^{34}$ cuando las obras que se querían realizar exigían el desplazamiento de centenas de viviendas. De esta manera, la amplitud de las intervenciones del SENARA se fue replanteando y redimensionando para desplazar menos hogares y para acoplarse al presupuesto asignado. Sin embargo, con estas modificaciones se reduce también la envergadura de las obras y los impactos deseados se vuelven menos ambiciosos. A lo largo del proyecto, el SENARA realiza cerca de cinco propuestas diferentes que se plantean al Banco Mundial.

El caso específico de Limón Ciudad Puerto es que está obligando al SENARA prácticamente a trabajar con pocos recursos, y lo que van a hacer es ¿qué? ¿Cuál es la palabra que cabe ahí? Una cochinada. ¿Y quién va a ser el que va a acuerpar, esencialmente el ridículo? El SENARA. Pero se tiene una ventaja, ¿sabe cuál es? Como Limón es la cenicienta, no importa ... Y así lo ve el gobierno de la República, así lo ve la presidencia de la República, así lo ve todo mundo (Representante del SENARA, abril de 2012).

En suma, el funcionamiento institucional del proyecto requiere de una UCP y de un sistema institucional reactivo, lo que no se confirmó, pero el lugar marginal de Limón dentro del contexto costarricense permite banalizar ese fracaso, tal y como lo muestra la citación anterior. La incapacidad para resolver el problema de las inundaciones pierde importancia en un contexto marginal, dentro de una región marginalizada.

\section{El control de la inundación y rivalidades sobre el riesgo}

Asimismo, a lo interno del subcomponente de Control de Inundación surgen muchos desacuerdos en cuanto a las soluciones que se deben aplicar ante el problema de las inundaciones, tal y como lo veremos en seguida. A pesar de proponérselo, el subcomponente de control de inundación, en el cual participan cuatro instituciones (el Ministerio de Vivienda y Asentamientos Humanos, la Municipalidad, JAPDEVA y SENARA), no logra establecer una coordinación interinstitucional en su ejecución.

En el trabajo de campo realizado se pudo observar que el subcomponente se caracteriza por relaciones de fuerza entre entidades que deben por ley 
cooperar con el SENARA (JAPDEVA, Municipalidad, MIVAH). El análisis de los correos institucionales entre JAPDEVA y el SENARA muestra por ejemplo que la Junta de Administración del puerto (JAPDEVA) no estaba en condiciones de responder a las solicitudes del subcomponente ${ }^{35}$. En los correos entre la Unidad Coordinadora (UCP) del PLCP y el SENARA, este último insiste en el atraso o en la ausencia de apoyo brindado por JAPDEVA ${ }^{36}$. La poca legitimidad de la UCP, responsable de facilitar esa coordinación interinstitucional en el subcomponente también influye en esa dinámica poco operante entre entidades públicas del proyecto.

Las diferencias interinstitucionales surgen igualmente por conflictos de poder sobre las obligaciones y los roles de cada entidad dentro del proyecto. Para mostrar mejor los desacuerdos dentro del subcomponente, es posible citar las diferencias entre lo que proponía el SENARA y por ejemplo la visión de la Municipalidad de Limón en relación a las inundaciones. Lo que está en juego es la manera en que cada institución se posiciona ante el riesgo: es decir la manera en que cada institución logra hacer valer su propia respuesta ante las inundaciones. Hay una rivalidad en relación al poder interpretar y dar sentido al subcomponente. Mientras que la entidad central enfatiza la importancia de ampliar los canales dentro de la ciudad (Canal Limoncito y Santa Rosa), varios representantes del gobierno local insisten en la importancia de consolidar los rompeolas ${ }^{37}$ para facilitar la salida del agua. En este sentido, un representante de la Municipalidad expresa:

La municipalidad los ha apoyado pidiéndoles permisos de paso a los vecinos para que ellos puedan pasar y hacer sus levantamientos. ... La parte de logística de permisos, la parte de sensibilidad de la gente más que nada. La parte técnica lo desarrolla el SENARA, ¿verdad? Nosotros lo que hacemos es un acompañamiento. ... Pero sí ha habido encontronazos. Más con una zona que es que la gente tiene la idea y el conocimiento de qué es lo que se tiene que hacer contra la parte técnica y que tal vez sugiere algo.

De esta manera, el funcionamiento del subcomponente no logra federar el conjunto de entidades competentes en torno a una visión de lo que se debe hacer para reducir el impacto de las inundaciones en territorios que, tal y como lo menciona el funcionario de la Municipalidad de Limón, también tienen una idea de lo que se debe realizar. Dentro de este contexto, el rol de la población en el proceso de ejecución del proyecto es definido por el mismo componente de control de inundación.

En efecto, a pesar de defender una participación de los habitantes en la formulación del proyecto, el rol activo de la población es limitado, su margen de

35 SENARA, Correo del 15 julio 2010 del Director de Ingeniería de JAPDEVA al Gerente del SENARA, Oficio GE-711-2010.

36 SENARA, Correo del 15 de febrero de 2011, del Coordinador de la Región Atlántica del SENARA al director de la UCP. Oficio: INDEP-RHAT-09-11.

37 Esta visión también es compartida por algunos de los representantes comunales. 
acción en la elaboración de propuestas técnicas es reducido. Paralelamente a las medidas que el SENARA quería llevar a cabo dentro del proyecto, los habitantes consideran que otras soluciones no estructurales se podrían realizar: mejorar la gestión de desechos y el manejo integrado de la cuenca. Pero estas propuestas de los habitantes de los barrios afectados por la intervención no consiguen hacerse escuchar. Las asociaciones de desarrollo juegan ciertamente un rol de intermediarios, pero este rol se hace a favor del trabajo de las instituciones. El rol de los representantes es el de facilitar el trabajo de la institución en el contexto de barrios considerados como difíciles y peligrosos. Cuando se trata de examinar el aspecto técnico de la intervención, la relación no es la misma:

Ellos a nivel técnico no aportan. Sí podrían, en el punto que es que ellos como miembro de la comunidad, conocen y hacen propuestas, pero en la parte social y eso es importante. Me pueden decir "vea es que, D. A. tiene un terreno donde pueden albergar casas, ¿por qué no hablan con ellos?". Esa es una propuesta técnica a un problema social. Las propuestas técnicas a nivel de infraestructura sí son hechas a lo interno de SENARA, ¿verdad? ... El problema es un problema social. El problema es que a uno le toca trabajar con las poblaciones más desprotegidas. ... Cuando yo le digo que en Limón es súper difícil, hablamos de trabajar en las comunidades con problemas sociales. ... Cuando hemos trabajado en Sixaola, en Siquirres, que trabajamos en finca, ya es otro concepto, ¿verdad? Hay un finquero, u otro parcelero ahí. Hay gente que tiene otro concepto. Pero ahí es trabajar en una zona poblacional, de alta densidad, con altas deficiencias, con problemática muy fuerte, ahí se hace todo inseguro (Representante del SENARA, abril de 2012).

Esta dinámica entre actores sociales e institucionales en la definición de lo que se debe hacer, sin llegar a un acuerdo, permite recordar a Bartolomé (2006, p. 136). La autora subraya no sólo que las formas de pensar la inundación dependen de la posición social, la inserción sociopolítica y la reflexividad de los actores, sino que además "las visiones de la inundación tienen más que ver con las coordenadas sociopolíticas específicas de la sociedad local que con el desarrollo del fenómeno en sí mismo y sus impactos sobre el entorno urbano...". De esta manera, el contexto social propio a los barrios periféricos de la ciudad de Limón influye en la manera en que se lleva a cabo el proyecto. Las medidas no estructurales van a perder fuerza y serán delegadas al trabajo cotidiano de la Municipalidad ${ }^{38}$. Es decir que, mientras que el referencial del PLCP desea ejecutar una intervención integrada y multisectorial en la cual se tome en cuenta las diferentes dimensiones del desarrollo territorial de Limón, la visión que se desprende efectivamente del subcomponente de control de inundación, tal y como se ejecuta, es la de una intervención técnica, unilateral,

38 Es importante indicar que el 7 de julio de 2012, la UCP apoya la organización de una jornada de limpieza de las riberas de los ríos, realizada por la comunidad y voluntarios de entidades públicas. Esta jornada cerró un ciclo de cinco talleres de capacitación sobre gestión de desechos. Pero lo que se busca enfatizar aquí es que dentro del Subcomponente en cuestión, esta temática, al no ser una técnica, nunca tomó fuerza. 
realizada por los ingenieros del SENARA. Pero esta entidad central, limitada en su margen de acción y poco familiarizada a las problemáticas urbanas de Limón, no logra aliar a todos los actores en torno al proyecto de intervención.

\section{El proyecto de "Limón ciudad Muerto"39}

Progresivamente, este contexto de diferencias y desfases genera que la población no se sienta más identificada al PLCP. Para los representantes de las asociaciones de Desarrollo, las prioridades del PLCP son ajenas a las de los habitantes de los barrios en cuestión. Para ellos, el proyecto no marca verdaderamente una ruptura con lo que se ha hecho hasta ahora. Durante el trabajo de campo, se observó que dentro de las comunidades existían dos consensos: la importancia de tomar en cuenta el manejo de los desechos y luego, la necesidad de una intervención. Si bien el contenido de esta última podía generar desacuerdos ${ }^{40}$, lo que se desprende del trabajo de campo es el sentimiento de fatiga por parte de los habitantes, ante el poco avance del proyecto. Los habitantes se cansan por la espera de un proyecto que no se concretiza:

El proyecto de las inundaciones, se le han hecho muchos estudios. ... en estos momentos, el proyecto de Limón Ciudad Puerto, yo lo veo como un, como una cosa sin fin, que no se ve caminar. Tal vez los estudios, tal vez las instituciones que están participando tienen el concepto de lo que se va a hacer, pero los habitantes de Limoncito no creen ya en el PLCP. Porque lo tenemos desde el 2007, con la cantaleta, ... ya llegamos al 2012, y ni se han arreglado las calles, ni los zanjos, ni se ve empezar el proyecto del alcantarillado de aguas negras (V., vecina de Limón y representante comunal, abril de 2012).

Este tipo de dinámica del proyecto reactiva la desconfianza de las poblaciones hacia las instituciones públicas. Para los habitantes de los barrios periféricos, el PLCP se convierte en un proyecto similar a los proyectos pasados: los ribereños no logran identificarse al PLCP y lo ven como un instrumento de retórica. En efecto, al presentar quejas por problemas comunales ante la Municipalidad, el gobierno local responde estar limitado por la ejecución del PLCP:

[N]osotros entendemos que ellos eso lo están utilizando como un portón, un portillo de escape, eso es una excusa para no hacer nada, porque eso no es cierto, por dos razones. La primera es que no todas las calles de la Colina están contempladas dentro del cronograma de PLCP. ... Ellos siempre siguen metiéndole a la gente y a las comunidades de que no se hace nada por esa razón. ... Lo otro es que ... nosotros les decíamos que mientras que llegue el proyecto de PLCP que tenemos más de ocho años de estarlo escuchando, ellos pueden perfectamente re-lastrar las calles. No les estamos pidiendo pavimentación de pronto, sino

39 Frase de Reynaldo, habitante de Cieneguita.

40 Como se mencionó anteriormente, algunos habitantes enfatizan el rol del rompeolas, que no estaba siendo contemplado por el SENARA. Pero estos desacuerdos, si bien existen, no generan una oposición frontal al proyecto. Los habitantes, en su mayoría, tienen la esperanza que cualquier intervención reduciría las inundaciones. 
relastreo de las calles, de las calles alternas de la comunidad (O., representante comunal de Colina, abril de 2012).

El proyecto se convierte progresivamente en una broma, una forma de ironizar sobre la práctica institucional considerada como ausente:

Entonces, mire, cuando uno habla algo de Limón Ciudad Puerto, ¿sabe qué hace la gente? Mejor se echa a reír, mejor se echan a reír. Y que me digan a mí. Cuando me dicen 'O., ¿pero por qué estas calles?'. Yo les digo 'bueno mire ahora tenemos un gran problema de que usted va a la municipalidad y a JAPDEVA, y a todo lado y lo primero que le dicen es: Limón Ciudad Puerto', que mientras que Limón Ciudad Puerto no hagan los trabajos, no van a arreglar nada. Entonces se echan a reír, y lo que dicen es 'diai entonces nunca vamos a ver nada aquí, porque ese PLCP tengo más de ocho años de estarlo escuchando y no se ve nada (O., representante comunal de Colina, abril de 2012).

\section{A modo de concusión}

Con este artículo se pretendió destacar el difícil proceso de ejecución de un proyecto de gran envergadura como lo fue el PLCP. Para esto se enfatizó principalmente el contexto en el que se inscribe el PLCP y se esclareció la escala más local. A partir del concepto de vulnerabilidad social e institucional, el objetivo fue situar al PLCP en un contexto relacional, el cual influye en la manera en que la no ejecución del proyecto es banalizada en un territorio marginal. Por su dinámica propia, el proyecto suscita tensiones que impiden el avance del proyecto, lo que despierta viejos fantasmas en una ciudad históricamente, rezagada en Costa Rica. De esta manera, la Contraloría General de la República (2012) concluye:

La escasa capacidad que se ha mostrado para ejecutar los recursos y desarrollar las obras, se da no obstante la importancia de los fines y objetivos del Proyecto, el cual está dirigido a una región del país que requiere un mayor desarrollo económico y social (CGR, Informe No. DFOE-SAF-IF-03-2012, 20 febrero de 2012, p. 25-26).

Como se dijo en introducción, el PLCP inicia un proceso de cierre en el 2014. El lapso establecido por el BM llega a su fecha de vencimiento con sólo un $30 \%$ de su presupuesto ejecutado. A la hora de su cierre, el gobierno de Costa Rica inicia otro proceso para realizar un nuevo proyecto y lograr ejecutar las obras prioritarias.

El caso de estudio permite, de esta manera, esclarecer esa relación estrecha entre estigmatización de un territorio, abandono estatal y vulnerabilidad. El peso de las relaciones estructurales entre el Estado y la población de la ciudad de Limón se refleja en la manera en que los actores interpretan y justifican prácticas, en este caso el poco avance del proyecto. Esto se hace en detrimento de los habitantes de los barrios periféricos, para quienes las condiciones de vida no cambian. La (in)acción estatal reproduce y profundiza el abandono en el que se encuentran estas poblaciones afectadas recurrentemente por las inundaciones urbanas en Limón. En el contexto de la Nueva agenda Urbana 
(Habitat III), el artículo espera proponer nuevos aspectos que se podrían tomar en cuenta en el desarrollo de futuros proyectos en las ciudades latinoamericanas. El desenlace del PLCP invita a reflexionar sobre la manera en que nuestras políticas públicas se plantean y logran incidir (o no) en los territorios marginalizados, complejos y numerosos de nuestra región.

El artículo espera dar una nueva lectura a la problemática de la gestión de riesgo en la ciudad, enfatizando no sólo las diferentes representaciones que existen sobre el riesgo, sino las dinámicas estructurales dentro de las cuales se encuentran dichas representaciones de riesgo y del territorio. El artículo explora así nuevos caminos de investigación en torno a la temática del riesgo en la ciudad, pues propone desplazar la mirada del investigador: el objeto central no es aquí las diferentes representaciones y estrategias ante el riesgo, sino el lugar de estas dentro de un contexto relacional complejo y dinámico que influye en la manera en que la vulnerabilidad de una población se forja y se reproduce.

\section{Referencias}

Argüello, Lavell. (2001). Internacionalización y globalización: notas sobre su incidencia en las condiciones y expresiones del riesgo en América Latina. Quórum, 3, (17), pp. 67-80.

Arroyo Gonzáles, N.(1995-1996). Sensores remotos fotográficos: zonificación por inundaciones en las cuencas bajas de los ríos Parrita y Limoncito: una caracterización socio-espacial mediante fotos aéreas y mapas. Revista Geográfica de América Central, 32-33, 165-181.

Bartolomé, Maria Alejandra. (2006). Pergamino, La Inundación Y Sus Versiones. Recuperado de http://www.scielo.org.ar/scielo.php?script=sci_arttext \&pid=S1851-16942006000100009

Beuscart, J. S. y Peerbaye, A. (2003). Urbanité(s) (avant-propos). Terrains \& travaux, 2, (5), 3-6.

Blaikie, I et al. (1994). At Risk : Natural Hazards, People's Vulnerability. Routledge, Londres.

Blanchon D., Gardin J. \& Moreau S. (Dir). (2011). Justice et injustices environnementales. Nanterre, Presses Universitaires de Paris Ouest, Collection Espace et Justice.

Banco Mundial. (2009). Competitividad en Costa Rica. Recuperado de http:// siteresources.worldbank.org/INTCOSTARICAINSPANISH/Resources/CostaRicaCompetitiveness.pdf

Banco Mundial. (2007). Project Appraisal Document on a proposed loan in the amount of US72.5 million to the Republic of Costa Rica for the City-Port of Limon 
Project (PAD), Report No: 41414 CR, 145p. Recuperado de http://siteresources. worldbank.org.

Banco Mundial. (2007). Project Information Document, appraisal stage, Repport No AB2830, "Costa Rica: City-Port of Limon Project". Recuperado de http://siteresources.worldbank.org.

Banco Mundial. (2003). Project Information Document, Concept stage, Report No: AB556. "Port-City of Limon Integrated Infrastruc". Recuperado de http://siteresources.worldbank.org.

Caballero Zeitún, E. (2013). Los riesgos urbanos y la justicia urbana en Centroamérica. Anuario de Estudios Centroamericanos, 39,11 27.

Carcache, P. (1984). Planificación Local, Renovación y Remodelación en la Ciudad de Limón. (Tesis de Licenciatura). Escuela de Ciencias Geográficas, Universidad Nacional, Costa Rica.

Contraloría General de la República (CGR). (2012). Informe No. DFOE-SAFIF-03-2012, 20 febrero, (2012). Informe del Estudio sobre la ejecución del Proyecto de Limon Ciudad-Puerto, División de Fiscalización Operativa y Evaluativa, Área de Fiscalización del sistema de Administración Financiera de la República.

Douglas M., Wildavsky A. (1982). Risk and Culture an Essai on the selection of technological and environmental dangers. Berkeley-Los Angeles-Londres, University of California Press.

Duchêne F., Coanus T., Martinais E. (1999). Les relations des gestionnaires du risque urbain avec les populations riveraines. Critique d'une certaine idée de la "communication. Les Annales des Mines, Responsabilité et Environnement, $n^{\circ} 13$, p. 5-17.

Duncan, Quince. (1995). "The Race Question in Costa Rica”. En Carlos Moore et al. (Ed.), African Presence in the Americas. Trenton, New Jersey: Africa World Press

Estado de la Nación. (2014). Vigésimo Informe Recuperado de http://www.estadonacion.or.cr/

Estado de la Nación. (2015). Vigésimo primer informe. Recuperado de http:// www.estadonacion.or.cr/

Fernández. (2008). Las identidades de la población de origen jamaiquino en el Caribe costarricense, 1872-1950. Revista de Historia, Número especial de diálogos, Noveno Congreso Centroamericano de Historia, Universidad de Costa Rica, San José, Costa Rica. 
FLACSO. (2004). Limón Ciudad Puerto. Informe de consultoría. Costa Rica.

Fonseca, Marinés. (2013). Políticas Públicas Regionales: Caso Limón CiudadPuerto, falta lugar, San José: Estado de la Nación en desarrollo humano sostenible, decimonoveno informe.

García Acosta, Virginia, Audefroy, Joel Francis \& Briones, Fernando (eds.). (2012). Social strategies for prevention and adaptation: Estrategias sociales de prevención y adaptación. México: Centro de Investigaciones y Estudios Superiores en Antropología Social [CIESAS].

García Acosta, Virginia. (2002). Historical disaster research. En Susannah Hoffman , Anthony Oliver-Smith (eds), Catastrophe \& Culture. The Anthropology of Disaster (Faltan las páginas del capítulo), Santa Fe: School of American Research Press / Oxford, James Currey, 312 p.

González, Armando. (24 de abril de 2011). Ciudad Puerto, La Nación, . Recuperado de http://www.nacion.com/archivo/Ciudad-puerto_0_1191280903.html

JAPDEVA. (1999). Plan regional de Desarrollo de la provincia de Limón, Limón hacia el siglo XXI, potencialidades y Oportunidades para el Desarrollo, 1999-2009.

JAPDEVA. (2011). Plan Regional de Desarrollo 2012-2022, Documento 1, Diagnóstico.

Jodelet, Denise. (2000). Representaciones sociales: contribución a un saber sociocultural sin fronteras. En Denise Jodelet y Alfredo Guerrero, Develando la cultura. Estudios en representaciones sociales, México: Facultad de Psicología-Universidad Nacional Autónoma de México, pp. 7-30.

Lavell, Allan. (2005). Los conceptos, estudios y práctica en torno al tema de los riesgos y desastres en América Latina: evolución y cambio, 1980-2004: el rol de la red, sus miembros y sus instituciones de apoyo. En La gobernabilidad en América Latina. Balance reciente y tendencias a futuro, Costa Rica: Facultad Latinoamericana de Ciencias Sociales[FLACSO],..

Leone, Frédéric y Vinet, Freddy (eds.). (2006). La vulnérabilité des sociétés et des territoires face aux menaces naturelles: Analyses géographiques. Publications de Montpellier III: Montpellier.

Ley 8725 (2009). Aprobación del Contrato de Préstamo N 7498-CR y sus Anexos, entre el Gobierno de la República de Costa Rica y el Banco Internacional de Reconstrucción y Fomento (BIRF), para financiar el Proyecto de Limón Ciudad Puerto. La Gaceta 112, 11 junio 2009.

Ley 4240. (1968). Planificación Urbana, La Gaceta, 15 noviembre de 1968. 
Lungo, Mario. (2001). Centroamérica. La ciudad y sus vulnerabilidades. Quórum, 3(17), 53-59.

Mansilla, Elizabeth. (2000). Riesgo y Ciudad. Universidad Nacional Autónoma de México, División de estudios de posgrado, Facultad de Arquitectura. Recuperado de http://www.desenredando.org/public/libros/2000/ryc/ RiesgoYCiudad-1.0.1.pdf

Meléndez, Carlos y Duncan, Quince. (2012). El negro en Costa Rica. San José: Editorial Costa Rica.

Municipalidad de Limón. (2012). Luchas y Esperanzas. 100 años de historia doble e inconclusa del Cantón de Limón. Costa Rica: Uruk Editores

Nahassia L. (2011). Estudio de percepción y de representación del riesgo de inundación por la población. SENARA: Proyecto de Limón Ciudad Puerto.

Plan Nacional de Erradicación de Precarios. (2008). Minuta de Reunión n², 2/05/2008, Limón.

Quesada Avendaño, Florencia. (2012). "Floods in Matina, Caribbean Coast of Costa Rica: Social Strategies for Prevention and Adaptation". En Virginia García Acosta, Joel Audefroy, F. \& Fernando Briones (coords.) Social strategies for prevention and adaptation: Estrategias sociales de prevención y adaptación (pp. 91-95). México: Centro de Investigaciones y Estudios Superiores en Antropología Social [CIESAS].

Rodríguez, Andrea. (4 de julio de 2014). Proyecto Limón Ciudad Puerto inicia proceso de cierre. La Nación. Recuperado de http://www.nacion.com/nacional/Proyeto-Limon-Ciudad-Puerto-ejecucion_0_1424657672.html

Ruiz Ramón, Gerardo. (20 de julio de 2014). 10 razones que provocaron el naufragio del proyecto Limón Ciudad Puerto, El Financiero, Recuperado de: http://www.elfinancierocr.com/economia-y-politica/Limon_Ciudad_Puerto-errores-Ministerio_de_Hacienda-Helio_Fallas-Contraloria_General_de_ la_Republica_0_557944201.html

Sala Constitucional, 2012, Sentencia n¹1985, 31 de agosto.

SENARA, Correo del 15 julio 2010 del Director de Ingeniería de JAPDEVA al Gerente del SENARA, Oficio GE-711-2010.

SENARA, Correo del 15 de febrero de 2011, del Coordinador de la Región Atlántica del SENARA al director de la UCP. Oficio: INDEP-RHAT-09-11.

SENARA, Expedientes $n^{\circ} 1$ a ${ }^{\circ} 7$ relativos al Proyecto de Limón Ciudad Puerto.

Wacquant, Loic. (2001). Los condenados de la Ciudad. Gueto, periferias y Es202 tado, Buenos Aires: Ediciones Manantial. 